\title{
Misiones de la Sanidad Militar, Especialidad fundamental odontología. Propuesta de empleo
}

\author{
Mombiedro Sandoval R. ${ }^{1}$
}

Sanid. mil. 2013; 69 (4): 266-273; ISSN: 1887-8571

\begin{abstract}
RESUMEN
En base a las necesidades operativas, se pretende hacer una revisión de las misiones de la odontología militar. Desde el punto de vista militar, la salud oral tiene unas consideraciones y unas repercusiones que le son propias. La odontología como parte integrante de la Sanidad Militar tiene como misiones conservar, recuperar, y seleccionar dentro del campo de su especialidad fundamental. Las funciones que desarrolla son: jurídico/pericial, preventiva, asistencial, formativa/docente y de investigación. Aún estando todas siempre presentes, adquieren una importancia variable según el escalón de apoyo logístico y las condiciones del despliegue, antes, durante o después. Se presentan unas conclusiones finales
\end{abstract}

PALABRAS CLAVE: Odontología militar, Asistencia dental, Dentistas militares, Misiones odontología militar.

Missions of Military Health Service. Essential branch Dentistry. Employment Proposal.

SUMMARY: A review of the odontology task is wanted to do based on operational needs. From the military point of view, the oral health has its own considerations and repercussions. The Dental Military Service (part of the military health), is responsable of the mantenance, treatment and selection within the field of his fundamental specialty. It is needed to perform the next functions: legal / expert, prevention, care, training / teaching and research. Theses functions, are always present, and have their own importance by logistical step and the deployment status, before, during or after. It is drawn some conclusion.

KEYWORDS: Military dentistry, Military odontology, Dental care, Dental assistant, Dentists, Dental military task.

\section{JUSTIFICACIÓN}

Son tres las circunstancias que han modificado en los últimos años el marco del ejercicio de la asistencia oral-bucal en las Fuerzas Armadas: traspaso de la responsabilidad en la asistencia logística operativa de la especialidad médica «estomatología» a la «odontología» que nace como una especialidad fundamental de la Sanidad Militar ${ }^{1-3}$ la incorporación de nuestro País a la Organización del Tratado del Atlántico Norte $\left(\right.$ OTAN/NATO) ${ }^{(1)}$ y por último la mayor profesionalización del militar ${ }^{(2)}$.

\footnotetext{
(1) El proceso se inició en septiembre del 1981 en el gobierno de Calvo-Sotelo (UCD) y se finalizó por el mismo gobierno en el 5 de junio 1982, se ratificó el 12 de marzo del 1986 cuando González Márquez (PSOE) hizo un referéndum para que la incorporación se realizara fuera de la estructura militar y con el objetivo de disminuir la presencia de tropas americanas en suelo español.

(2) La disposición adicional decimotercera de la Ley 17/1999, de 18 de mayo, de Régimen del Personal de las Fuerzas Armadas, determinó la suspensión de la prestación del servicio militar, regulada en la Ley Orgánica 13/1991, de 20 de diciembre, del Servicio Militar. Con el Real Decreto 247/2001, 9 de marzo, se adelantó la suspensión de la prestación del servicio militar (no abolición) el 31 de diciembre de 2002.
}

\footnotetext{
Tcol. Médico Estomatólogo. Ministerio de Defensa. Gabinete Odontológico. Madrid. España.

Dirección para correspondencia: Rafael Mombiedro Sandoval. Ministerio de Defensa. Gabinete Odontológico. Castellana n ${ }^{\circ}$ 109. 28046 Madrid.

Recibido: 25 de marzo de 2013

Aceptado: 20 de mayo de 2013
}

Esto ha conducido a la aparición de unos facultativos con diferente perfil profesional, con necesidades formativas nuevas y con una carrera profesional propia. El militar profesional será desplegado en operaciones (con frecuencia multinacionales) dentro y fuera del territorio nacional y trabajará en un marco doctrinal compartido con otras Fuerzas Armadas de países aliados, fruto de nuestros compromisos internacionales. Las necesidades operativas hacen que la asistencia facultativa odontológica se dirija a personas que presentan unas necesidades de salud oral específicas y diferentes a la de la población general.

La importancia de salud general y en especial de la oral, desde el punto de vista militar tiene unas consideraciones y unas repercusiones que le son propias y que le caracterizan. El soldado o marinero requieren un estado de salud general y oral en particular, suficiente para poder entrenar y participar en ejercicios, maniobras y despliegues, porque el fin último es tener un estado de salud y una condición física y mental adecuada a la misión a realizar, en ocasiones en ambientes hostiles y austeros, con apoyos limitados. Es por ello que tener un buen estado de salud oral dentro de las Fuerzas Armadas (FFAA.), es un requisito que supone una condición previa a la incorporación a los Ejércitos ${ }^{4,5}$.

Una vez incorporado a la vida militar, este concepto de salud, adquiere mayor significación en ciertas circunstancias, como son: Personal de vuelo y paracaidismo, personal de buceo y de submarinos y en los despliegues o maniobras ${ }^{6-9}$. Se persigue que la consecución del objetivo, o misión militar, no pueda ser retrasada o menoscabada por un problema de salud dental prevenible $^{10}$. 


\section{Misiones de la Sanidad Militar, Especialidad fundamental odontología. Propuesta de empleo}

La pérdida de la salud oral y la necesidad de asistencia subsiguiente, condicionan el apoyo sanitario-odontológico. Este apoyo está presente en todas las fases de las operaciones (antes, durante, después), y por principio debe ser de la misma calidad y competencia que en territorio nacional, solo otras prioridades o condiciones del despliegue o del medio son las que pueden condicionar la asistencia ${ }^{11,12}$.

El despliegue de recursos Sanitarios (Odontológicos) materiales y humanos (cuantitativos y cualitativos) en la zona de operaciones presenta repercusiones logísticas y operativas y viene definido entre otros por dos factores: uno es la necesidad de asistencia prevista (número y tipo de bajas esperado) y el otro a los equipos o unidades odontológicas necesarias (personales y materiales) para satisfacer la demanda. A mayor y más sofisticada necesidad de asistencia, mayor cantidad y más especialización de los medios materiales y profesionales requeridos ${ }^{11-13}$.

Una de las causas de asistencia estudiadas ha sido la presencia de dolor. En los estudios sobre emergencias dentales en civiles y en militares, la aparición de dolor como causa de la asistencia, oscilaba entre el 25 y el $50 \%$ de las causas de solicitar tratamiento $^{14-17}$.

En la tabla 1 se presenta una clasificación de las repercusiones del dolor oral en operaciones.

Las repercusiones que para el «servicio» supone la presencia de dolor son difíciles de cuantificar, por un lado tenemos los aspectos físicos y psicológicos y por otro los cambios en la conducta secundarios a la pérdida de salud. Entre los primeros se puede incluir, la preocupación, la incapacidad para su trabajo, la perdida de sueño y la fatiga subsiguiente. En los cambios de conducta se podría incluir el tener que solicitar asistencia facultativa, el evitar algunos alimentos y la necesidad de medicación analgésica y antibiótica (se asociarían los efectos secundarios a los fármacos utilizados). Todos estos factores, contribuyen a una disminución en la «operatividad», se pierde capacidad de concentración, y resistencia a la fatiga, lo que incrementa el menoscabo psicológico asociado a la presencia de dolor ${ }^{18-20}$.

El dolor y sus repercusiones, influyen en la calidad de vida del soldado/marinero, interfiriendo en las relaciones sociales y laborales, incrementando el absentismo y/o el escaso rendimiento laboral, e incluso pudiendo ser causa de baja laboral o de pérdida temporal de la «aptitud para el servicio» ${ }^{10,11,21,22}$.
En operaciones ante una emergencia el primer paso a seguir, es la solicitud de asistencia. Se realiza a través de las transmisiones de la Unidad (empleo de la radio o teléfono o incluso la telemedicina), podrá ser seguida de la evacuación, lo que supone una necesidad de transporte (convoy terrestre o helicóptero) hasta el escalón sanitario logístico superior adecuado a la situación clínica. Se puede llegar incluso a necesitar la repatriación del paciente ${ }^{12}$.

En operaciones del ejército americano con submarinos las emergencias dentales fueron responsables del $9 \%$ de las causas de evacuación ${ }^{23}$. En las operaciones en el Ejercito de Tierra correspondientes a las denominadas «Libertad duradera», «Libertad para Irak» y en «Afganistán» desde el 2003 al 2005, el número de aeroevacuaciones fuera del teatro de operaciones vario entre 1,1 a 21 personas por 1000 soldados y año, lo que representó un promedio de $2,1 \%$ de todas las causas de aeroevacuación ${ }^{24,25}$.

El ejército Francés en Afganistán, diciembre 2009-febrero 2010, presentó una tasa de emergencias dentales de 293/1000 soldados/año. El 65\% requirieron evacuación médica (MEDEVAC) en helicóptero ${ }^{26}$.

Dentro de las repercusiones de una emergencia dental habría que incluir además de las del afectado, las pérdidas de disponibilidad que afectan a los escoltas y acompañantes. Se incluirían los tiempos de trabajo y de descanso del personal que no se pueden realizar, las logísticas (transporte, comida, cama), y los riesgos inherentes a cualquier movimiento por la zona de operaciones. Todos ellos son aspectos de difíciles de cuantificación ${ }^{15,20,27-30}$.

El cálculo de los días de baja del servicio por necesitar asistencia dental de emergencia en ejercicios tácticos, fue evaluado en un estudio retrospectivo por Payne y Posey en $1981^{31}$. Para una incidencia de 167 emergencias dentales / 1000 soldados / año, la pérdida de tiempo de servicio fue de 121,5 días / 1000 soldados/ año, es decir que a cada emergencia dental (sin incluir tiempos de transporte o de desplazamiento) le correspondió 0,72 días de servicio perdido ${ }^{31}$.

Los días de baja post exodoncia quirúrgica de los terceros molares se analizaron en un estudio longitudinal de 11 meses, en 14.500 reclutas finlandeses de 20 años de media de edad, los días de baja oscilaron entre 4,6 días de promedio en las cirugías complicadas a 1,7 días en las exodoncias simples ${ }^{32}$.

Las consecuencias de la baja temporal o definitiva de un soldado requerirían estudios más específicos.

TABLA 1. Repercusiones del dolor oral en operaciones.

\begin{tabular}{lll}
\hline \multicolumn{1}{c}{ PERSONALES } & \multicolumn{1}{c}{ LOGÍSTICAS } & \multicolumn{1}{c}{ OPERATIVAS } \\
\hline Psicológicos: & Transmisiones: & $\begin{array}{l}\text { Ausencia / baja operatividad de uno de sus } \\
\text { miembros: }\end{array}$ \\
- Irritabilidad & - Locales en el TO. & - Sobrecarga a los compañeros \\
- Desánimo & - Internacionales & La misión se ejecuta con retraso, se realiza de \\
- Deterioro del descaso y del sueño & & forma incompleta, o se incumple \\
- Fatiga precoz & Telemedicina $4^{\circ}$ escalón $(H C D G U):$ & \\
- Falta de concentración, alerta y rendimiento. & - Desplegar recursos Materiales y personales & \\
Físicos: & Transporte para la evacuación: & \\
- Altera la alimentación & (a otro escalón más retrasado) & \\
Efectos $2^{\circ}$ al tto farmacológico: & - Al enfermo y a la escolta \\
- Somnolencia & - Incluso fuera del TO, caso de la repatriación \\
- Molestias digestivas & & \\
\hline
\end{tabular}

TO: Teatro de operaciones. HCDGU: Hospital Central de la Defensa Gómez Ulla. 


\section{R. Mombiedro Sandoval}

En todo proceso de asistencia facultativa, se consumen recursos (personales, materiales y tiempo) y por lo tanto se pueden llegar a sobrecargar y a saturar los servicios sanitarios propios o de los aliados 13,20,27,28.

La falta de salud oral presenta otras consecuencias asociadas a la ausencia o pérdida de la operatividad de un miembro del equipo, son también de difícil valoración, pero en líneas generales siempre se sobrecarga a los compañeros y lo que reviste una mayor trascendencia, puede haber un tiempo en el que la eficiencia y eficacia de la Unidad pueden verse comprometidas, tanto más, si la misión o la maniobra no es que quede retrasada o incompleta, sino que no se pueda cumplir ${ }^{10}$.

Las repercusiones directas e indirectas referidas anteriormente, están asociadas a consumo de recursos. Estos gastos suponen costes de personal, material y tiempo dedicado a esta actividad sanitaria odontológica.

La deseable cuantificación del coste total de estas consecuencias son específicas en cada una de las operaciones o misiones, su análisis pormenorizado implicaría el diseño y la realización de nuevos estudios especializados

Por lo expuesto se resalta la importancia de poder limitar los esfuerzos de apoyo sanitario solo a las emergencias que por su naturaleza sean imprevisibles, (fracturas dentales, pérdidas o rotura de obturaciones, aflojamiento o descementación de prótesis, infecciones agudas, lesiones en accidentes de tráfico, caídas, peleas, deportes, enfermedades, heridas de combate) ${ }^{17,24,25,33}$.

En el ejército francés en Afganistán, diciembre 2009-febrero 2010 , cerca del $80 \%$ pudieron ser prevenibles ${ }^{26}$. En el ejército español, Bosnia-Heezegobina, enero-febrero 2001, para una tasa de incidencia de 304 asistencias / 1000 soldados /año, se calculó que el $60 \%$ fueron prevenibles $^{17}$.

Surge así el concepto de «desplegabilidad» o aptitud para el despliegue, donde la salud oral (dental fitness) es un aspecto más dentro del concepto de salud general (medical readiness) $)^{10-12}$

El servicio Logístico de Sanidad, tiene entre otros cometidos proveer con arreglo a los principios logísticos de apoyo sanitario, unos cometidos, misiones u objetivos dirigidos a la selección, conservación y recuperación y de los efectivos personales. En nuestro caso, aplicados a la especialidad fundamental de Odontología ${ }^{1-3,12}$.

Las funciones, acciones o las actividades de la Sanidad Militar deben dar satisfacción a las misiones u objetivos. Con la aplicación de medidas preventivas, conservamos la salud oral. Prestando la necesaria asistencia facultativa, recuperamos, hacemos retornar al paciente a un mejor estado de salud oral. Con la función jurídico/pericial se valora, selecciona y se satisfacen numerosos aspectos íntimamente ligados a la Sanidad Militar.

\section{FUNCIONES DE LA ODONTOLOGÍA}

Se aprecian cuatro tipos de funciones: Jurídico/pericial $^{4-12,21,22,35-39}$, Preventiva ${ }^{17-20}$, Asistencial ${ }^{21-23}$, Formativa (puesta al día), docente y de investigación ${ }^{24,25}$.

Las cuatro son primordiales tanto en las Bases como en Despliegues u Operaciones; el escalón, el momento del despliegue (antes, durante, después), las condiciones de vida y la necesaria adaptación al momento, harán que se dé prioridad a una sobre la otra, a efectos prácticos, es imposible separar completamente unas de las otras. Cualquier asistencia facultativa lleva implícita una tarea administrativa, son en general aspectos jurídicos - legales y en ocasiones periciales. De la asistencia surge inevitablemente una terapéutica o consejo preventivo.

Cualquier acción preventiva nace de unas necesidades de salud y se acompaña de unos inexcusables matices educativos y legales. Por último estas actividades debidamente procesadas, pueden y deben constituir elemento de investigación y docencia.

Se comprende entonces que el orden de presentación puede no corresponder con las prioridades planteadas.

La colaboración y participación con organismos civiles en acciones de peritación, prevención, asistencia, o de formación, pueden resultar provechosas e instructivas para ambas partes.

\section{Función Jurídico-Pericial}

Se incluye en este epígrafe la selección de personal, valoración de las lesiones en «acto de servicio». La identificación dental en campaña o catástrofe. También incluiría asesorar al mando en aquellos asuntos relacionados con la salud oral que sean de su competencia ${ }^{4-12,21,22,35-40 .}$.

La documentación sanitaria odontológica (ficha odontológica) comprende en todos los casos la historia dental, el registro del odontograma y periodontograma, radiografías, fotografías, consentimientos informados, y en cada caso particular lo que le corresponda: aptitud psicofísica, aptitud para el despliegue, vuelo, paracaidismo, buceo y embarque en submarinos. La futura y necesaria informatización, cambiará el manejo de la información y aportará sin duda ventajas de gran alcance.

\section{Función Preventiva}

El esfuerzo de mantener la asistencia odontológica de calidad en toda la cadena logística, hacen aconsejable incrementar las acciones preventivas en orden de disminuir la incidencia, es decir la aparición de nuevas patologías, y con ello la necesidad de nueva asistencia ${ }^{41-46}$.

Desde un $40 \%$ hasta un $80 \%$ de las emergencias en despliegues están ocasionadas por causas que pueden ser prevenibles ${ }^{17,20,26,31,47}$.

Hay muchos factores que condicionan la comparación de los diferentes índices de asistencia. Unos estarían ligados a la demografía de la población desplegada (edad, sexo, nivel cultural), otros a las condiciones del despliegue (operaciones de interposición y reconstrucción, combate, facilidad de uso del servicio de salud oral), otros factores estarían relacionados con el concepto de asistencia o de emergencia dental, por otro lado los estudios prospectivos resultan más controlados. El factor más estudiado ha sido el estado previo de salud previo al despliegue. Cuando en operaciones se despliega personal con buen estado de salud oral (clase1) o en un estado de salud oral que no sea previsible la necesidad de asistencia (clase 2), el número de emergencias dentales fue de hasta 7 veces menor que cuando se desplegaban en mal estado de salud oral (clase 3) o presentaban 


\section{Misiones de la Sanidad Militar, Especialidad fundamental odontología. Propuesta de empleo}

un estado de salud oral desconocido, o la aptitud dental había caducado (clase 4) ${ }^{17,20,48-51}$.

No solo hay que obtener un estado de salud oral que no dificulte o retrase la maniobra, hay que mantener este buen estado de salud, esto hace que la medicina preventiva y la vigilancia epidemiológica, adquieran una importancia clave ${ }^{47}$.

Se tenderá hacia aquellas medidas de medicina preventiva encaminadas a reducir los factores de riesgo y por otro lado a incrementar el estado de salud y bienestar del personal militar. Con ello se pretende disminuir la incidencia de enfermedades o lesiones que causan dolor, y/o malestar bucal, disminuir la necesidad de asistencia en operaciones y a frenar o limitar la minusvalía o mutilación ${ }^{41-46}$.

\section{Educación, formación, motivación}

Es una tarea individual cuando se atiende a un paciente, pero también colectiva. En estos casos, se debe dirigir de una forma específica para cada grupo de riesgo ${ }^{52}$.

\section{Eliminación ó control de la placa bacteriana I biofilm ${ }^{41-46}$}

Consejo dietético, (reducción del metabolismo bacteriano por reducción en la ingesta de dieta cariógena)

Cepillado, seda o cepillo interdental (control de placa)

Empleo de antisépticos locales: Agentes catiónicos, agentes aniónicos, agentes no iónico de control de placa.

\section{Fortalecimiento del huésped. Empleo de fluoruros ${ }^{47,53}$}

La caries está causada por cierto tipo de bacterias (estreptococcus mutans y lactobacilus) que viven en la boca. Cuando se adhieren a los dientes forman la placa dental (biofilm) Las bacterias utilizan los hidratos de carbono de los alimentos (azucares, frutas, pan, pasta, arroz,...) y producen ácidos como resultado del metabolismo-digestión. Estos ácidos pueden penetrar en la sustancia dura de los dientes disolviendo parte de los minerales (calcio, fosfatos). Si los ataques son infrecuentes, de corta duración y la saliva aporta minerales (flúor) se reemplazan los perdidos por el diente y se reparan las lesiones iniciales no habiendo pérdida de estructura dental.

\section{Exámenes en salud, detección precoz ${ }^{21,37}$}

Exámenes ordinarios o extraordinarios. Cumplimentar la ficha odontológica.

\section{Detección de pacientes de riesgo}

Para la aplicación de medidas específicas de profilaxis y del tratamiento individualizado más adecuado. Para ello se propone la valoración o clasificación de riesgo de caries ${ }^{41,42-45,54-56}$ y de riesgo periodontal ${ }^{44}$, que se presentan en las tablas 2 y 3 .

\section{Confección de la estadística sanitaria ${ }^{46}$}

Estudios epidemiológicos en territorio nacional y en despliegues (longitudinales y transversales): Índices de la necesidad de tratamiento, y vigilancia epidemiológica en territorio nacional y en despliegues.

\section{Planificación, dirección y ejecución de estrategias de salud buco dental $^{46,52}$}

Las actividades educativas, divulgativas se dirigirán a la mejora en el control de la placa bacteriana y de todos aquellos elementos que sean causas o factores de riesgo de patología oral.

La formación y la actualización de los facultativos y la colaboración con instituciones Militares y Civiles, con las que se comparten objetivos sería altamente beneficiosa.

La integración con otras áreas de promoción de la salud, (tabaco, dieta, higiene personal) hace a las medidas más eficaces y se tiene más probabilidades de éxito.

Tabla 2. Clasificación de los pacientes por el riesgo de caries $^{41,42-45,54-56}$

\begin{tabular}{|c|c|c|}
\hline RIESGO BAJO & RIESGO MEDIO & RIESGO ALTO \\
\hline $\begin{array}{l}\text { - Sin caries en los últimos tres años } \\
\text { - Superficies adecuadamente restauradas } \\
\text { - Fosas y fisuras amplias o selladas } \\
\text { - Buena higiene oral } \\
\text { - Visitas regulares al dentista } \\
\text { - Uso adecuado de flúor }\end{array}$ & $\begin{array}{l}\text { - Al menos una caries tratada en el último año } \\
\text { - Fosas y fisuras estrechas o no selladas } \\
\text { - Aceptable higiene oral } \\
\text { - Visitas irregulares al dentista } \\
\text { - Uso inadecuado de flúor } \\
\text { - Raíces expuestas } \\
\text { - Manchas blancas localizadas } \\
\text { - Incipientes radiolucideces interproximales } \\
\text { - En tratamiento de ortodoncia }\end{array}$ & $\begin{array}{l}\text { - Caries presente } \\
\text { - Márgenes abiertos o desbordados } \\
\text { - Fosas y fisuras estrechas y profundas } \\
\text { - Mala higiene oral } \\
\text { - Visitas irregulares al dentista } \\
\text { - No uso o uso inadecuado de flúor } \\
\text { - Raíces expuestas o caries de raíces tratadas } \\
\text { - Manchas blancas generalizadas } \\
\text { - Radiolucideces interproximales } \\
\text { - Frecuente consumo de azucares, más de tres } \\
\text { bebidas o comidas azucaradas al día }\end{array}$ \\
\hline
\end{tabular}

Otros factores que suponen alto riesgo de caries:

Altos títulos de bacterias cariogénicas (estreptococo mutans, lactobacilos), bajo flujo de saliva en reposo o bajo estimulación, prolongada lactancia, familiares con antecedentes de mala salud, presencia de displasias del esmalte, anomalías genéticas en los dientes, muchas superficies restauradas, en tratamiento contra el cáncer, desordenes de la alimentación, alcoholismo y drogas de abuso. 


\section{R. Mombiedro Sandoval}

Tabla 3. Factores de riesgo (FR) periodontales ${ }^{44}$

\begin{tabular}{|c|c|}
\hline FR del comportamiento & $\begin{array}{l}\text { Tabaco/fumadores* } \\
\text { Ausencia de visitas regulares al dentista** } \\
\text { Deficiente higiene oral** }\end{array}$ \\
\hline FR locales & $\begin{array}{l}\text { Enfermedad dental no tratada** } \\
\text { Restauración dental defectuosa** } \\
\text { Factores anatómicos: Maloclusión, } \\
\text { furcación*** }\end{array}$ \\
\hline FR microbiólogos & $\begin{array}{l}\text { Presencia de patógenos periodontales* } \\
\text { Presencia de biofilm potencialmente } \\
\text { patógena** } \\
\text { Intensa carga bacteriana** }\end{array}$ \\
\hline FR sistémico & $\begin{array}{l}\text { Diabetes mellitus* } \\
\text { VIH *** } \\
\text { Osteoporósis** }\end{array}$ \\
\hline FR genéticos & $\begin{array}{l}\text { Sexo Hombre** } \\
\text { Raza africana** }\end{array}$ \\
\hline
\end{tabular}

\section{Función Asistencial ${ }^{12,57-59}$}

Suponen un mínimo esencial deseable para cada uno de los escalones, se verían modificadas según la capacitación profesional, dotación de material, ambiente y la fase de la operación en la que surja la necesidad asistencial (antes-territorio nacional, durante y después del despliegue). El mando determinará en cada caso las prioridades, el nivel de asistencia que se requiere y los recursos disponibles.

Cualquiera de los escalones puede adquirir completa o parcialmente alguna de las capacidades correspondientes al escalón superior. Esto es más factible en territorio nacional, o en despliegues más estables y no alteraría el principio de progresión del apoyo.

Los objetivos finales de la función asistencial, serían:

1 Recuperar para el servicio lo antes posible al personal militar.

2. Mejorar el dolor y evitar y/o limitar las lesiones de los tejidos blandos y duros.

3. Evitar evacuaciones a otros escalones más retrasados.

4. Diagnóstico y tratamiento en primera instancia, antes de la evacuación a otro Escalón.

5. Evitar innecesaria mutilación dental.

6. Colaborar en el diagnóstico y en el nivel de evacuación que se requiere en cada momento.

Estados y patologías contempladas:

1. Lesiones de origen no traumático: Pulpitis, absceso dental, absceso periodontal, pericoronaritis $\left(3^{\circ}\right.$ molares parcialmente erupcionados), gingivitis úlcero necróticas (GUN).

2. Lesiones de origen traumático: Luxación de la articulación témporo mandibular, pérdida de una obturación, fractura dental (coronal-radicular), desplazamientos dentarios, luxación o avulsión dentaria, fracturas dentoalveolares, lesiones en partes blandas.

3. Prótesis dentales: fractura o descementación.

4. Profilaxis antitetánica, tratamiento antibiótico, y con analgésicos y antiinflamatorios.

5. Colaborar con otras especialidades en el triage (clasificación) de las víctimas y en las medidas de soporte vital.

6. Colaboración en las medidas de salvar y mantener la vida:

Primeros auxilios, (STANAG 2122), Primeros auxilios en guerra NBQ, mantenimiento de la vía aérea, estabilización de la ventilación pulmonar, detener hemorragias, inmovilización de fracturas, y cuidado de lesiones mayores en partes blandas, iniciar el tratamiento del shock, iniciar el tratamiento de las quemaduras, iniciar el tratamiento de las congelaciones, control de la infección, tratamiento del dolor, corrección de la deshidratación.

A los apartados 5-6 se les puede considerar objetivos / misiones secundarios, extras, o accesorios, y a los 4 primeros como objetivos odontológicos primarios o principales.

En algunos ejércitos aliados de la NATO / OTAN, se diferencia entre odontólogo y el cirujano oral odontólogo. Este último despliega en escalones donde se hace cirugía oral ( $3^{\circ}$ escalón); En nuestro caso el perfil profesional de los estomatólogos se adapta más a los segundos y como es un diploma a extinguir, se requeriría la formación de los odontólogos en esta área de la patología oral.

\section{Función asistencial por escalones:}

\section{$1^{\circ}$ Escalón y $2^{\circ}$ escalón ligero.}

Aunque no exista Oficial Odontólogo ni dotación de material específico, la definición de la función asistencial, debiera quedar establecida, por dos razones:

1. Porque el personal sanitario desplegado tendría que estar entrenado para poder tratar o evacuar a los casos absolutamente urgentes. La formación teórico práctica para el personal sanitario (no odontólogo), en esta área debería estar normalizada.

2. Otros ejércitos de nuestro entorno OTAN/NATO, si despliegan oficiales odontólogos en este escalón.

a) Misiones primarias:

- Identificación y valoración de las lesiones máxilo faciales y puesta en evacuación.

- Cuidados dentales iniciales o asistencia dental primaria. Se entiende que se refiere a los tratamientos dentales absolutamente urgentes. El tratamiento sintomático del dolor y de la inflamación oral-dental y el drenaje de abscesos serían posibles en este escalón.

b) Misiones accesorias:

- Son misiones que no le son propias a su especialidad fundamental. No se plantean al no existir Oficial Odontólogo desplegado. Dado el caso que por alguna razón este estuviera presente, su misión seria ayudar al Oficial Médico en las medidas de salvamento y de mantenimiento de la vida.

c) Debería estar dotado de material para:

- La exploración oral y anestesia local, tratamiento agudo de lesiones mucosas, periodontales y pulpares, exodoncia no quirúrgica, medidas de mantenimiento de la vida, como son el mantenimiento de la vía aérea y la resucitación cardiovascular: Instrumentos para retirar los fragmentos móviles en la vía aérea, y estabilización de las partes blandas desplazadas, inmovilización de fracturas simples maxilofaciales, perdida y reposición de fluidos, cricotirotomia, prevención del shock. También debería disponer de vendaje de campaña, vacuna antitetánica, antibióticos y analgésicos no esteroideos. 


\section{Misiones de la Sanidad Militar, Especialidad fundamental odontología. Propuesta de empleo}

- Los fármacos disponibles y el nivel de esterilización es el del $1^{\circ}$ escalón médico. La dotación es para 30 pacientes / día.

\section{$2^{\circ}$ Escalón reforzado.}

Normalmente constituido por los Escalones Médicos Avanzados y los Equipos de Cirugía Avanzados ${ }^{12}$.

a) Misiones primarias:

- Identificación (no dispone de medios para el diagnóstico), valoración e inicio de tratamiento (estabilización) de las lesiones máxilo faciales, y evacuación cuando las condiciones lo permitan. Es mejor diferirlo al siguiente escalón lo antes posible.

- Tratamiento dental de emergencia.

b) Misiones accesorias:

- Ayuda al oficial médico en las medidas de salvamento y de mantenimiento de la vida.

- Deberá estar dotado de material para:

- Exploración y anestesia dental.

- Tratamiento agudo de lesiones y enfermedades mucosas, periodontales y pulpares.(sintomático y etiológico): inicio del tratamiento pulpar, obturaciones provisionales, cementación de coronas y puentes descementados)

- Exodoncia no quirúrgica.

- Exploración, diagnóstico y estabilización de las lesiones maxilofaciales (cuando se retrase la evacuación, el oficial odontólogo, podrá efectuar la reaproximación e inmovilización de las fracturas mandibulares)

- Este nivel, está dotado además para realización de traqueotomía y ventilación con presión positiva.

- Equipo básico y suministros generales.

- Realización de medidas de prevención y de profilaxis especificas (antitetánica, antibióticos, analgésicos-antiinflamatorios-antipiréticos)

- La disponibilidad de fármacos y la esterilización es la que le corresponde al $2^{\circ}$ escalón médico. La dotación es para 30 pacientes /día.

\section{$3^{\circ}$ Escalón.}

a) Misiones primarias:

- Identificación e inicio de tratamiento de las lesiones máxilofaciales, el tratamiento definitivo se puede realizar cuando las lesiones óseas y mucosas no sean importantes. Se retrasaría pues la evacuación hasta donde, se dispone de anestesia general, de radiodiagnóstico y de facultativos especializados. Es preferible diferirlo al $4^{\circ}$ escalón, en los 2-4 días siguientes, donde se podrá completar el diagnóstico y el tratamiento adecuado.

- Tratamientos dentales urgentes y programados no urgentes.

b) Misiones accesorias:

- Ayuda al oficial médico en las medidas de salvamento y de mantenimiento de la vida. Deberá estar dotado de material para:
- Exploración y anestesia dental.

- Tratamiento dental de emergencia y programadas no urgentes

- Tratamiento agudo y definitivo de las lesiones mucosas, periodontales y pulpares.

- Exodoncia, incluso la quirúrgica.

- Restauración temporal y definitiva.

- Tratamiento pulpar definitivo.

- Tratamiento definitivo, periodontal y de las mucosas.

- Reparación provisional de prótesis removible.

- Cementado de prótesis fijas descementadas.

- La disponibilidad de fármacos, y la esterilización es el que corresponde a un $3^{\circ}$ nivel médico. La dotación disponible es para 30 pacientes / 24 horas

$4^{\circ}$ Escalón.

Localizados en la Red Hospitalaria Militar, con especialistas en cirugía Maxilo Facial y en Cirugía Plástica.

En este escalón, se llevarían a cabo las misiones de la Sanidad Militar, dentro de la especialidad fundamental de OdontologíaEstomatología, en el ámbito: jurídico-pericial, preventivo, formativo (puesta al día), docente, de investigación y de asistencia, que le corresponderían por su nivel o escalón de apoyo Sanitario.

Este tendrá capacidad para el tratamiento integral y definitivo de las lesiones del aparato estomatognático en todos los campos de la especialidad.

Se realizan los tratamientos dentales y se colabora como ayuda a otras especialidades para terminar o completar el tratamiento definitivo de las lesiones máxilo faciales. Un aspecto que define la asistencia de la especialidad Odontología-Estomatología de $4^{\circ}$ escalón, es la necesidad de:

- Colaboración de otros servicios hospitalarios.

- Medios no disponibles en otros escalones.

- Ser el último escalón del Apoyo Sanitario.

Se expone una lista de estados o patologías contempladas. No es una lista cerrada, y se vería modificada por el estado actual del ejercicio profesional, por las necesidades cambiantes en cada momento y por los recursos empleados:

1. En los traumatismos máxilo faciales y en las cirugías del aparato estomatognático se aplicaría los protocolos pre y post quirúrgicos para la rehabilitación funcional y morfológica precoz y así poder completar el tratamiento definitivo. En las cirugías máxilo faciales y plásticas y reparadoras, se emplearán las técnicas de reconstrucción facial con epítesis.

2. Odontológicamente, la asistencia comprende la reposición protésica fija/removible. Se incluye la fase quirúrgica preprotética (torus, implantes, regeneración ósea...) y la protésica propiamente dicha. Desde el punto de vista facial, la reposición con epítesis.

3. Tratamiento de ortodoncia antes y después de la cirugía ortognática en los casos de lesiones en las que estuviera indicado.

4. Diagnóstico y tratamiento de las enfermedades periodontales. 
5. Todas las actividades de diagnóstico y tratamiento en cirugía y medicina oral.

6. Colaboración en el diagnóstico y en el manejo de los pacientes con dolor crónico del aparato estomatognático. Dolor miofascial, fibromialgia, artritis, artrosis,..... Se debe forma parte de la unidad funcional de dolor oralfacial.

7. Asistencia dental con anestesia general a pacientes que lo requieran.

8. Pacientes oncológicos con tratamientos de quimio-radioterapia. Aplicación de los protocolos de profilaxis y tratamiento.

9. Pacientes con síndrome seco. Aplicación de protocolos de profilaxis y de confort.

10. Cuadros de aumento de la resistencia periférica al paso del aíre en el sueño, SAOS, (hipopnea, apnea del sueño, ronquido). Se debe forma parte de la unidad funcional del Sueño junto Neurofisiología, Neumologia, ORL, ...

11. Boca séptica, foco sépticos y su imbricación en cirugías cardiovasculares, en oftalmología (coriorretinitis), ORL (sinusitis), cardiopatías y cuadros de isquemia periférica.

12. Pacientes con cuagulopatías o en tratamiento con anticoagulantes.

13. Pacientes con alteración del sistema inmune.

14. Servicio de Odontología legal y forense:

- Valoración de las lesiones en acto de servicio (valoración del daño corporal), y de los diferentes conceptos ligados al de aptitud (ingreso, aptitud psicofísica, despliegue, submarinos, buceo y vuelo).

- Registro central de información dental.

- Participación en los equipos de identificación de víctimas (pre-post mortem).

\section{Función formativa, puesta al día; docente y de investigación ${ }^{24-25}$}

La Sanidad militar puede realizar esta misión de una forma interna, formando a todos los oficiales con recursos propios, y externa, enviando a los oficiales a tiempo parcial o completo de forma temporal a los centros u organismos a determinar, son opciones complementarias, de ninguna forma excluyentes.

El perfeccionamiento y la formación continuada, puesta al día, es indispensable para cualquier actividad, la participación en cursos reuniones, conferencias, cursos, ..., de carácter científico, debiera ser periódica y obligatoria, para lo que supondría el perfil del Oficial odontólogo - estomatólogo militar.

\section{CONCLUSIONES}

El despliegue al teatro o zona de operaciones de una persona con procesos odontológicos agudos supone una baja y una necesidad de asistencia segura.

Los problemas operativos y las dificultades técnicas de la pérdida de la salud oral en maniobras, despliegues o ejercicios tácticos, tiene repercusiones, médico-legales, preventivas y asistenciales.
El tratamiento de situaciones complejas, requiere profesionales entrenados e instrumental adecuado, condiciones no siempre disponibles en el teatro de operaciones.

Los avances en la prevención generalizada, la detección de grupos de riesgo, y el tratamiento de las lesiones más prevalentes, podrían ser prioritarios en el control de las patologías de la población diana.

El tener como objetivo el »mantenimiento de la salud oral», es un elemento que contribuye a una mayor presencia de la Sanidad Militar en el apoyo a la Fuerza y puede suponer un incentivo para el alistamiento y el mantenimiento del compromiso de los militares profesionales.

\section{BIBLIOGRAFIA}

1. Ley 17/1999 de 18 de mayo de Régimen del Personal de las Fuerzas Armadas. BOD 97 (20-05-1999).

2. Real Decreto 207/2003. Reglamento de Cuerpos, Escalas y Especialidades de las Fuerzas Armadas. BOE 55 (5-3-2003).

3. Real Decreto $711 / 2010$, de 28 de mayo, por el que se aprueba el Reglamento de especialidades fundamentales de las Fuerzas Armadas. BOE $n^{\circ} 133$. (106-2010).

4. Orden PRE/2622/2007, de 7 de septiembre. «Cuadro médico de exclusiones exigible para el ingreso en los centros docentes militares de formación». Boletín Oficial de Defensa, $n^{\circ} 183$ (18-09-2007).

5. Resolución 452/38001/2008 de 11 de enero, de la subsecretaría, por la que se convocan las pruebas selectivas para el ingreso en los centros docentes militares de formación para el acceso de nacionales y extranjeros a la condición de militar de tropa y marinería. BOE $n^{\circ} 15$ (17-01-2008).

6. Real Decreto 944/2001 de 3 de agosto. Reglamento para la determinación de la aptitud psicofísica del personal de las Fuerzas Armadas». Boletín Oficial de Defensa, $n^{\circ} 155$ (08-08-2001).

7. $\mathrm{OM} \mathrm{n}^{\circ} 282 / 82$, de 20 de octubre. Normas sobre la aptitud para el Buceo. Diario Oficial de Marina ${ }^{\circ} 251$ (2-11-1982).

8. OM (D) 614/09377/88. Norma sobre la aptitud para el personal de submarinos BOD no 100 (16-05-1988).

9. Orden Ministerial 23/2011, de 27 de abril, por la que se aprueban las normas para la valoración de la aptitud médica del personal de las Fuerzas Armadas con responsabilidad de vuelo. BOD n 88 (06-05-2011).

10. North Atlantic Treaty Organization (NATO). Military Agency for Standardization (MAS) STANAG 2466 MEDSTD (Edition 2) Dental fitness standards for military personnel and a dental fitness classification system. NSA(MED)1004(2007)MEDSTD/2466. (05-Nov-2007).

11. North Atlantic Treaty Organization (NATO). Military Agency for Standardization (NSA). MAS STANAG MED/2228 (Edition 2). Allied joint Medical Support Doctrine-AJP-4.10(A).(3 -03- 2006).

12. Ejército de Tierra. Mando de Adiestramiento y Doctrina. PD4-616. Sanidad en Operaciones. Resolución 552/02143/11. Boletín Oficial de Defensa ${ }^{\circ}$ 28 (10-02-2011) y Ejército de Tierra. Mando de Adiestramiento y Doctrina. OR7-603. Orientaciones. Sanidad en Operaciones. Resolución 552/18773/03. Boletín Oficial de Defensa n⿳亠丷厂 222 (13-11-2003).

13. Charlton DG, Ehrlich AD, Ragain JC, Lyles MB, Roberts HW. Evaluation of field dental equipment in a deployment environment. Mil Med 2006;171:261-267.

14. Keller DL. Reduction of dental emergencies through dental readiness. Mil Med 1988;153:498-501.

15. Gibson GB, Blasberg B, Hill SJ. A prospective survey of hospital ambulatory dental emergencies. Part1: patient and emergency characteristics. Spec Care Dentist 1993;13:61-65.

16. Scully C. The pattern of patient attendance for emergency care in a British dental teaching hospital. Community Dent Health 1995;12:151-154.

17. Mombiedro R, Llena C. Emergencias orales en los militares españoles desplegados en Bosnia Herzegovina. Incidencias durante 9 semanas (2000-2001). RCOE 2007; 12:237-244.

18. Spalj S, Pric D, Mlacovic Zrinski M, Bulj M, Plancak D. Predictive value of dental readiness and psychologica_l dimensions for oral health-related qual- 


\section{Misiones de la Sanidad Militar, Especialidad fundamental odontología. Propuesta de empleo}

ity of life in Croatian soldiers: a cross-sectional study. Croat Med J. 2012 Oct;53(5):461-9.

19. Locker D, Grushka M. The impact of dental and facial pain. J Dent Res 1987;66:1414-1417

20. Teweles RB, King JE. Impact of troop dental health on combat readiness Mil Med 1987;152:223-225.

21. Instrucción técnica $n^{\circ} 6$ de la Inspección General de Sanidad (IGESAN), sobre «Requisitos sanitarios exigibles al personal militar que se desplace a zonas de operaciones» (15-07-2011).

22. Instrucción número 169/2001, de 31 de julio, del Subsecretario de Defensa, por la que se dictan normas sobre la determinación y el control de las bajas temporales para el servicio por causas psicofísicas del personal militar profesional. BOD n ${ }^{\circ} 158(13-08-2001)$

23. Deutsch WM. Dental Events during Periods of isolation in the US submarine force. Mil Med 2008;173:29-37.

24. Mitchener TA, Hauret KG, Hoedebecke EL, Darakjy S, Jones BH. Air medical evacuations of soldiers due to oral-facial disease and injuries, Operations Enduring Freedom/Iraqi Freedom. Mil Med. 2008 May;173(5):465-73.

25. Mitchener TA, Hauret KG. Air medical evacuations of soldiers for oral-facial disease and injuries, 2005, Operations Enduring Freedom/Iraqi Freedom. Mil Med. 2009 Apr;174(4):376-81.

26. Gunepin M, Deache F, Ausset I, Berlizot P, Simececk J. The Rate of dental emergencies in french armed forces. Deployed to afghanistan. Mil med 2011;176:828-832

27. Bishop BG, Donnelly JC. Proposed criteria for classifying potential dental emergencies in Department of Defense Military Personnel. Mil Med 1997;162:130-135.

28. Callison GM. A system for tracking dental readiness in the Air Force Reserve. Mil Med 1998;163:239-243.

29. Rodden JW, Simecek JW. Dental emergency visits o Marine corps personnel. Mil Med 1995;160:555-557.

30. Deutsch WM, Simecek JW. Dental emergencies among Marines ashore in Operations Desert Shield/Store. Mil Med 1996;161:620-623

31. Payne TF, Posey WR. Analisis of dental casualties in prolonge field training exercises. Mil Med 1981;146:265-267

32. Rajasuo T. Treatment of third molars in Finnish conscripts. Mil Med 1994;159:426-429.

33. Becker T, Ashkenazi M. Incidence of reported dental trauma among soldiers during basic training. Mil Med 2009;2:190-192.

34. Instrucción número 169/2001, de 31 de julio, del Subsecretario de Defensa, por la que se dictan normas sobre la determinación y el control de las bajas temporales para el servicio por causas psicofísicas del personal militar profesional. BOD n ${ }^{\circ} 158$ (13-08-2001)

35. North Atlantic Treaty Organization (NATO). Military Agency for Standardization (MAS) STANAG 2464 MEDSTD (Edition 2) (Ratification draft 1) Military Forensic Dental identification. NSA(JSB)1050-MED/2464.(8-Dec-2003)

36. Guía de identificación de víctimas de catástrofes. Organización internacional de policía criminal (INTERPOL) 1997. Disponible en: http://www.interpol. int/pv_obj_cache/pv_obj_id_53DD0CC6D61BE68B32C0B4DDECDF4786 2BB60700/filename/GuideEs.pdf

37. Instrucción técnica de 7 de febrero de 2006 de la Inspección General de Sanidad (IGESAN), sobre la ficha de identificación sanitaria ( FIS) y huella genética (07-02-2006).

38. RD 2394/04 de 30 de diciembre. Protocolo para la recuperación, identificación, traslado e inhumación de los restos mortales de los miembros de las FF. AA., GC, y CN de P, fallecidos en operaciones fuera del territorio nacional. BOE 13 (15-01-2005)
39. Real Decreto 32/2009, de 16 de enero, por el que se aprueba el Protocolo nacional de actuación Médico-forense y de Policía Científica en sucesos con víctimas múltiples. BOE 32 (6 febrero 2009)

40. Pachar J.V., Bryan K. El sistema de apoyo internacional para la gestión forense de cadáveres en situaciones de desastre: La experiencia de Haití, 2010. Cuad. med. Forense [revista en la Internet]. 2010 Jun [citado $2010 \mathrm{Sep}$ 07] ; 16(1-2): 81-95. Disponible en: http://scielo.isciii.es/scielo.php?script=sci arttext\&pid=S1135-76062010000100009\&lng=es. doi: $10.4321 / \mathrm{S} 1135$ 76062010000100009.

41. Mongeau SW. USAF dental readiness classifications and caries-Risk assessment. Mil Med 2008;173:42-47.

42. Fontana M, Zero DT. Assessing patients caries risk. J Am Dent Assoc 2006;137:1231-1239.

43. Journal of the California Dental Association. 28-02-2013 último acceso. Disponible en home page http:// www.cdafoundation.org/journal.

44. American Academy of Periodontology (AAP). An interactive risk assessment, text is available at: www.perio.org/consumer/4a.html. 01-03-2013.

45. No authors listed-anónimo. Caries diagnosis and risk assessment. A review of preventive strategies and management. J Am Dent Assoc 1995; 126 Suppl: $1 \mathrm{~S}-24 \mathrm{~S}$.

46. Chaffin J.Dental Population Health Measures: Supporting ArmyTransformation. Mil Med 2003;168(3):223-226.

47. Cuenca E, Manau C, Serra Ll. odontología preventiva y comunitaria. Principios, métodos y aplicaciones. $2^{\text {a }}$ Ed. Barcelona: Masson; 1999.

48. Chaffin J, King JE, Fretwell LD. Army dental emergency rates in Bosnia. Mil Med 2001;106:1074-8.

49. Richardson PS. Dental Risk Assessment for Military Personnel. Mil Med 2005; $170: 542-545$

50. Keller DL. Reduction of dental emergencies through dental readiness. Mil Med 1988;153:498-501

51. Allen FW, Smith BE. Impact of dental sick call on combat effectiveness: The dental fitness class 3 soldier. Mil Med 1992;157:200-203.

52. Van der Wal H, Basic N, Loomans S, van der Schans C, van der Meer R. Promoting oral hygiene behavior in recruits in the Dutch Army. Mil Med 2009;9:971-976.

53. Teich ST, Aizenbud D, Gutmacher Z. Guiding the practitioner through the caries management by risk assessment (CAMBRA) protocol. Alpha Omegan 2011;104:68-72.

54. American Dental Asociation (ADA). Caries risk assessment forms can be found at http://www.ada.org/2752-aspx?current tab=2. Último acceso 28-02-2013.

55. Caries managemant by risk assessment (CAMBRA). Guidelines published in the american dental asociation journal, can be found at: http://www.cdafoundation.org/journal. Último acceso 28-02-2013.

56. Julihn A, Agholme MB, Grindefjord M,Modeer T. Risk factors and risk indicators associated with high caries experience in Swedish 19-year-olds. Acta Odontol Scand 2006;64:267-273.

57. North Atlantic Treaty Organization. (NATO). Military Agency for Standardization. MAS (Edition 2) (Ratification draft 1). The extent of dental - and maxillofacial treatment at role 1-3 medical support. AmedP-35. NSA(MDE)0568 MEDSTD/2453. Unclassified. (31-May-2011).

58. North Atlantic Treaty Organization. (NATO). Military Agency for Standardization. MAS (Edition 3). Ratification Draft 1. Tasks and Skills For Appropriate Staffing Of Dental Personnel For Operational Deployment. AMedP-36. NSA(MDE)0570(2011) MEDSTD/2465. Unclassified. (31-May-2011)

59. Norma técnica $15 / 02$ sobre la Organización y funcionamiento de los servicios de odontología en el Ejército de Tierra (30-12-2002). Derogada. 